\title{
AN OUT-PATIENT ANAESTHETIC SERVICE: STANDARDS AND ORGANIZATION
}

\author{
E. JAMES TRELOAR, M.D. ${ }^{*}$
}

WITH THE ADVENT of modern anaesthetic techniques out-patient anaesthesia is not only possible but also desirable. For example, the apprehensive patient with multiple dental fillings to be done can be handled in one session. In this type of case the patient may be saved four to six months of weekly dental visits with the associated psychic trauma. Another facet of out-patient anaesthesia worthy of consideration is that each patient, dental or surgical, treated in this manner is saved one or more hospital days.

In the organization of an operative clinic for out-patient surgery and dentistry many factors must be considered. However, there are three rules which must be followed. They are: (1) to preserve and protect the well-being of the patient; (2) to make the operative procedure painless; (3) to provide adequate operating conditions.

There can be no doubt that any hazard to life from out-patient surgery or dentistry done under general anaesthesia is related to the latter factor. It is felt that out-patient anaesthesia should not offer the patient any less safety than he would have in the hospital, or at least it should offer the same degree of safety as is hospital standard for the community in which he is living. For this reason, the anaesthesiologist should work in those conditions with which he is most familiar and which he considers most suitable for the safety of the patient. He should then be responsible for the organization and design of the operative clinic. Poole, et al., in their paper on this subject, offer an excellent guide for those wishing to set up such a clinic. ${ }^{1}$ Finally, it should be noted that only a competent and well-trained physician should undertake to perform the anaesthesia and he, by preference, should have certification or fellowship in this field.

The purpose of this paper is to describe an out-patient clinic at present directed by the writer and his associate, Dr. P. W. Klassen. This service has been functioning in Vancouver since July, $1965 .^{2}$

\section{Anaesthesia and OUt-Patient Surgery or Dentistry}

\section{Design}

The arrangement of the operating room facilities should be such as to comply with the rules stated above. A sample layout is shown in Figure 1. It will be noted that patients in the recovery area can be seen from all locations and are kept under surveillance at all times until they are fully awake.

-750 West Broadway, Vancouver 9, B.C.

Can. Anaes. Soc. J., vol. 14, no. 6, November, 1967 


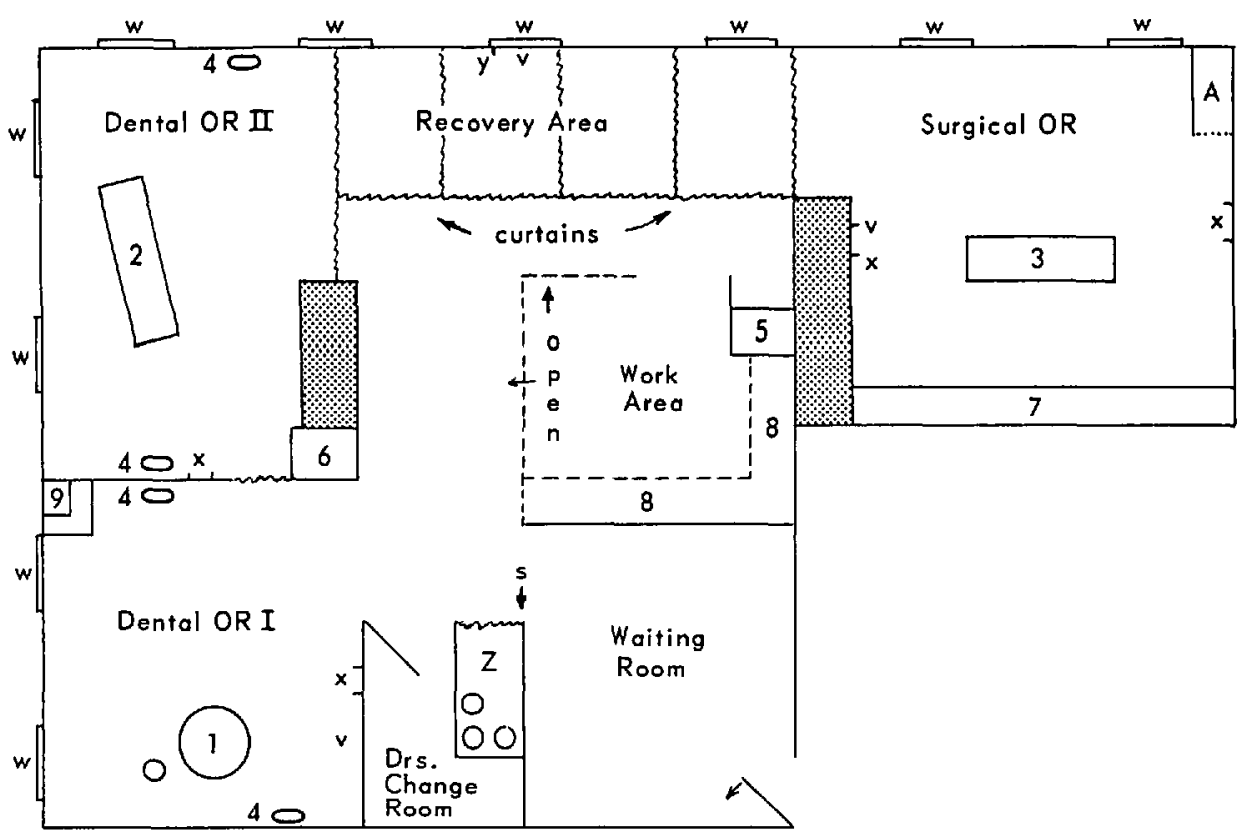

FIgURE 1. Out-patient clinic for general anaesthesia (approximately 1100 square feet; $1^{\prime \prime}=10^{\prime}$ ). 1. Dental chair. 2. Operating table. 3. Operating table. 4. Wash sinks. 5. Surgical scrub sink. 6. Supply cupboard. 7. Surgical shelves. 8. Work counters. 9. Suction machine and high-speed air compressor. $Z$. $\mathrm{O}_{2}$ and $\mathrm{N}_{2} \mathrm{O}$ storage. $x . \mathrm{O}_{2}$ and $\mathrm{N}_{2} \mathrm{O}$ outlets. v. Suction outlets. y. $\mathrm{O}_{2}$ outlet only. A. Autoclave. W. Window. S. Sliding door.

\section{Patient Instructions}

The patient should be given, by his own doctor, a sheet of instructions (supplied by the anaesthesiologist) which clearly tells him where and when to report and other factors of importance. An example of such instructions is given in Figure 2.

\section{Patient Admission to the Clinic}

When the patient arrives in the office for out-patient anaesthesia, he is met by the nurse who obtains pertinent data with regard to his age, address, insurance plan, etc. At this time she collects the general service charge and obtains a surgical consent form (Fig. 3 ).

The patient is then prepared for physical examination and dressed in a patient gown. Premedication, if desired, is given at this time. The patient is interviewed and examined, and factors pertinent to preoperative assessment are recorded. ${ }^{3}$ Failure to examine the patient preoperatively and to obtain a history leaves the anaesthesiologist open to serious charges. This is particularly so when he may be the only physician who has seen the patient preoperatively, for example, a dental case. The criminal code states in section 45 :

Everyone is protected from criminal responsibility for performing a surgical operation upon a person for the benefit of that person if:

A. The operation is performed with reasonable care and skill. 
PREOPERATIVE INSTRUCTIONS FOR PATIENTS ON DAY OF SURGERY

OR DENTAL WORK

1) Morning patients should take nothing by mouth after midnight.

2) Afternoon patients may have light breakfast. Stomach should be empty 5 hours preoperatively (that is, nothing by mouth).

3) Patients are to report thirty minutes preoperatively. Operative time $\ldots \ldots \ldots \ldots \ldots$. Report at $\ldots \ldots \ldots \ldots$

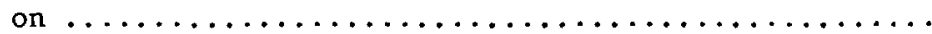

4) Patients should arrange for a friend or relative to take them home. Driving is prohibited postoperatively.

5) The general service charge for the use of these facilities is $\$ 10-\$ 20$ and should be paid preoperatively. This is separate from the anaesthetic fee and is not covered by medical insurance.

6) Medical insurance numbers should be brought to avoid unnecessary billing.

7) Patients should wear casual comfortable clothing and shoes.

Figure 2

I HEREBY GIVE AUTHORITY TO

TO PERFORM SUCH SURGERY AS HE CONSIDERS NECESSARY.

I ALSO AUTHORIZE AOMINISTRATION OF GENERAL ANAESTHESIA BY A MEMBER OF THE ANAESTHETIC SERVIOE.

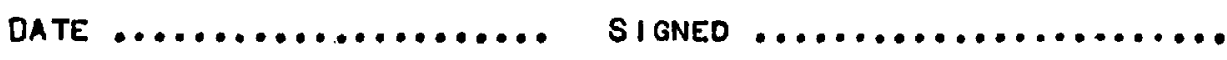

WI TAESSEO

FOR

RELATIONSHIP

Figure 3 
B. It is reasonable to perform the operation having regard to the state of health of the person at the time the operation is performed and to all the circumstances of the case.

Thus, it is mandatory that the anaesthesiologist be fully cognizant of the state of health of the patient. When this examination is finished and duly recorded the patient is taken to the operating room.

\section{Methods of Induction and Maintenance}

There are various techniques of anaesthesia possible for out-patient work and these will vary with the experience of the anaesthesiologist and the condition of the patient. The method described below was chosen as a safe, efficient anaesthetic technique and has been used as a basis for over 1500 cases. Of course there must be flexibility, and for a very robust male some intravenous Demerol is useful. For the procedure to be completed by mask alone it is often desirable to add a little gallamine (20-30 mg.) to make it easier to assist ventilation.

Methohexital (Brietal) is used for induction of anaesthesia. This is because it is thought to be metabolized more rapidly ${ }^{4}$ than thiopental although others disagree with this opinion. 5 The dosage used is approximately $1 \mathrm{mg}$. per pound of body weight but this may be varied within reason to suit the needs of the particular case. A I per cent solution is used, so that a 150-pound patient would be given $15 \mathrm{ml}$.

Methohexital is much more stable in solution (mixed with water for injection) than is thiopental. It is possible to keep it in solution for several weeks with no noticeable crystallization or loss of effect. It is also said by the manufacturer to be less irritating to the tissues. Occasionally, on injection the patient will complain of a pain up the arm but we have noted no such complaints postoperatively.

The onset of action is swift, just as with thiopental. However, in the dosage described above, spontaneous ventilation usually continues and there is seldom a significant fall in blood pressure. Central nervous system stimulatory effects may be noted as soon as the patient is asleep. There is often considerable twitching and spasmodic movement of the limbs, but this effect is transient. Diaphragmatic spasm may occur but always disappears as the anaesthetic is supplemented with nitrous oxide and halothane. Postoperatively, patients treated with methohexital are ambulatory much more rapidly than those given thiopental.

When the patient is to be intubated, succinylcholine is used in an appropriate amount (30-60 mg. for the average adult). There seems to be some relationship between the size of the dose and the degree of the postoperative muscular stiffness, so if the anaesthesiologist is skilful, it is well to keep the amount of relaxant down to the bare minimum requirement. Decamethonium bromide could equally well be used, but while this is fine in children with their somewhat higher metabolic rate, we have found that adults (40-50-year age group) complain of weakness or that their "legs are gone." For this reason and because it is twice as expensive as succinylcholine, we have limited its use.

For maintenance of anaesthesia, halothane (Fluothane) is used in a mixture of nitrous oxide and oxygen in proportions of $2 \mathrm{~L}$. nitrous oxide to $1.5 \mathrm{~L}$. oxygen. 
Percentages vary from 0.5 to 1.5 and may be less for a minor surgical procedure. With these agents and perhaps a little atropine $(0.4 \mathrm{mg}$.) preoperatively, the patient may be awake at the end of the procedure and ready to leave the operative clinic in 30 to 60 minutes. It should be noted that all agents used are nonexplosive.

It is quite possible to supplement these anaesthetic agents with others such as methoxyflurane (Penthrane) and/or intravenous meperidine (Demerol). Whether there is any economic or other advantage to this has not yet been determined.

\section{Features Relating to the Anaesthesia}

All equipment must be kept scrupulously clean. Sterile disposable needles are used for routine injections. Syringes are autoclaved as a unit, i.e., with the barrel in situ. Endotracheal tubes are soaked in green soap solution. They are then scrubbed inside and out and boiled for at least ten minutes. The same applies to metal connectors. Anaesthetic tubing and masks are washed after each case.

For dental cases which are going to be bloody and of some duration a nasotracheal tube is inserted. It is selected so that it will cause minimal trauma to the nose, thus decreasing the incidence of nose-bleed and postoperative discomfort. A slightly smaller tube is employed than would be used for orotracheal intubation, and ventilation is assisted if necessary. With the tube in place and the patient well ventilated, a damp throat pack is carefully inserted. It is most important to be certain that this pack has a string or tape attached which remains outside the mouth at all times.

Some patients are anaesthetized in a dental chair, and no continuous intravenous infusion is run, but this should be available for immediate use if required. The chair should be such that it can be readily tipped head down, and the anaesthesiologist should be completely familiar with its operation.

All patients are closely watched with regard to ventilation, pulse, and blood pressure. Pulse monitor, electrocardiograph, electroencephalograph and a defibrillator are available on the premises. Also available are cardiac drugs (Table I) which might be required in the event of cardiac arrest. One weak link which might occur in minor out-patient procedures is the inability of the dentist or

TABLE I

Cardiac Drugs Which Should Be Avait.able

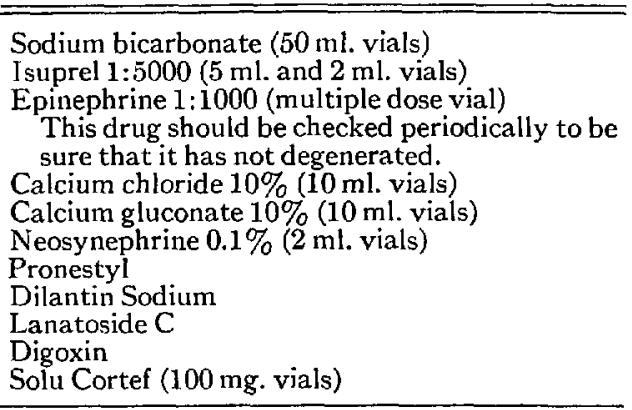


surgeon to respond adequately in the event of cardiac arrest. Even when told what to do by the anaesthesiologist, his experience and training may be so limited that he cannot properly perform an external cardiac massage. This would indicate the need for increased exchange of information between those experienced in operating room procedures and those with less experience.

On completion of the operation, the patient is removed from the operating table or dental chair to a stretcher onto which he is secured. It is felt best that the patient should be in the semi-prone position, particularly dental patients where there is a possibility of postoperative bleeding and aspiration. Once the patient is in the correct position with good and adequate ventilation assured, he is removed to the recovery area and there kept under observation at all times until his reflexes have returned. The recovery area is equipped with oxygen and suction.

Whenever a procedure of several hours' duration is being performed, the patient must be closely watched for possible damage to peripheral nerves and other tissues from undue prolonged pressure. The anaesthetic tubing and connectors should be placed on sponge rubber pads so that they do not press on the patient's face. The elbow should be placed on sponge rubber pads or pillows and the legs should be uncrossed. In the chair, if the legs fall apart and the ankles are unduly everted then the knees should be strapped lightly together (avoid possible peroneal nerve damage). One should be alert to possible danger to the eyes at all times, and they must be well protected.

Children of all ages are handled in much the same manner, and the presence of the mother or father with the child during induction is often as effective as is a narcotic. In general, it has been found unnecessary to give a child an injection prior to induction, since it only adds to his fright. "Premedication" in those cases where a narcotic, atropine, or phenothiazine is desired, can be given immediately following induction. The increased blood flow in subcutaneous tissues at this time leads to very rapid uptake.

Finally, the anaesthesiologist must keep a good and adequate record. This should include his preoperative assessment and examination of the patient, the drugs and amounts used for induction (flow rates, etc.), and the anaesthetic procedure. For example, "Orotracheal, intubation, mask only," or "Epidural." In addition, a record should be kept of the course of anaesthesia, drugs administered, and unusual events. This record should also include details of the postoperative period such as nausea, vomiting, or any undue complaints.

\section{Complaints}

The anaesthesiologist operating an out-patient service has a much closer relationship to the patient than does the hospital anaesthesiologist. He must be prepared to seek out and explain to the patient any complaints which may arise. It is good public relations, when a patient has had a long three- or four-hour procedure, to contact him at home on the day of his operation or the following day and inquire as to his well-being. The following are some complaints that have been noted among some 1500 cases. 


\section{Muscular Stiffness}

This is related to the administration of succinylcholine; it appears very quickly in the younger individual, but in the older person (over 40) it may not appear until the next day. The most commonly used description of this complaint is, "I feel like I have been beaten all over-what did you do to me?" The explanation is usually well accepted.

Treatment. Some anaesthesiologists feel that there is a relationship between muscle stiffness and the amount of the drug used, as mentioned above. Certainly, if one gives repeated injections there seems to be more of this complaint. The use of a minimal quantity, say $30 \mathrm{mg}$, in an adult female of 110 to 120 pounds is sufficient for the experienced anaesthesiologist. Explanation that stiffness will pass in 24 hours and that a hot bath is helpful, and perhaps for the severe case Meprobamate $400 \mathrm{mg}$. q.i.d. has been sufficient treatment.

\section{Sore Throat}

Even in the best of hands this complaint occurs from time to time. It is more evident in an out-patient department where narcotics and other sedatives are used minimally if at all. Rather than dwell on the details of the endotracheal intubation, which some people find abhorrent, it is usually sufficient to explain that a throat pack was used to prevent blood, teeth, fillings, etc. from going down the wrong way and that this has caused some irritation.

Treatment. Very little is needed over and above reassurance for the throat is usually better by the next day. However, for the more severe case one can suggest the use of steam inhalation.

\section{Pain in the Temporomandibular Joint}

Following a very long dental filling procedure where the mouth has been propped open for several hours this complaint may arise. The symptoms begin on the day following the procedure and may be quite severe.

Treatment. The condition is self-limiting and usually resolves in 7 to 10 days. In the meantime, it is well to rest the jaws from excess talking, chewing, etc. Heat and A.S.A. are useful.

\section{Nause and Vomiting}

The degree and amount of postoperative nausea and vomiting seems to be directly related to the length of the surgery. It is aggravated by movement, so that when the patient is dressing postoperatively it is usually at its peak. In procedures of under one hour's duration vomiting is a rare occurrence.

Treatment. For the long procedure a small amount of phenothiazine just after induction (e.g. Stemetil 3-5 mg. intramuscularly) may help. However, this will prolong the awakening time. We have not yet been able to find any agent or drug that can give continuously good results for this complaint.

\section{Headache}

This occurs occasionally but does not seem to last long.

Treatment. A.S.A. with codeine gr. $\%$, as required. 


\section{Types of Operations Which May Be Done on an Out-patient Basis}

The field of surgery and dentistry which may be accomplished is limited only by the amount of hospital-type postoperative care that the patient may require. Certain procedures can be done and the patient admitted to a private hospital. In over 1500 out-patient procedures the operations listed in Table II have been successfully performed.

TABLE II

Operations Performed on an Out-patient Basis

\begin{tabular}{lc}
\hline \hline Head and neck & Rectal \\
Eyes & Sigmoidoscopy \\
E.U.A. & Excision of external hemorrhoids \\
Removal of chalazion & Excision of fistula in ano \\
Naso-lacrimal probing & Cauterization of anal warts \\
Ears & Gynaecological Procedures \\
Myringotomy and insertion of tubes & E.U.A. \\
Syringing of ears & D.and C. (diagnostic) \\
Removal of foreign bodies from the ear & Removal of I.U.D. \\
Removal of blood clots after injury to ear & Cauterization of perineal warts \\
drums & Biopsy of tumour of recto-vaginal septum \\
Nose & Perineal nerve block \\
Cauterization of turbinates & \\
Rhinoplasty & Miscellaneous \\
Reduction of fractured nose & Excision of ganglia \\
Nasal septal reconstruction & Removal of screws and pins used for bone \\
Sub mucous resection & fixation \\
Excision of nasal polyps & Removal of nails and curetting of nail beds \\
Nasal antral windows & Dorsal slit of the penis \\
Throat & Circumcision \\
Tonsillectomy (special cases only) & \\
Adenoidectomy & Orthopaedic Procedures \\
Direct laryngoscopy and biopsy & Bilateral Keller (2 stages) \\
Mouth & McBride bunionectomy \\
Excision of tumours of the oral cavity & Excision of tendon sheath \\
Dental extractions & Change of plaster \\
Dental fllings & Excision of exostoses \\
Alveolectomy & Manipulation under anaesthetic \\
Phrenectomy & Secondary tendon repair \\
Trunk & Plastic surgical procedures \\
Breast Biopsy & Excision of facial scars \\
Removal of miscellaneous tumours & Dermabrasion \\
\hline
\end{tabular}

${ }^{1}$ Where adequate post-operative care is available in the home.

Of course, there are many more procedures which could be done on an outpatient basis. Breast biopsies can be done with minimal delay. This would seem to offer relief from anxiety for many women who at present must wait one or two weeks before anything is done. If malignancy is found then arrangements can be made for immediate admission on an emergency basis.

\section{SUMMARY}

An out-patient anaesthetic service has been described. Simple rules for the operation of the service have been given and the reasons for certain standards 
pointed out. Anaesthetic techniques are described and some of the possible procedures listed.

\section{RÉSUMÉ}

Avec les techniques modernes d'anesthésie, l'anesthésie en clinique externe est non seulement possible mais également souhaitable. Tout malade traité de cette façon sauve une ou plusieurs journées d'hospitalisation. Un malade craintif qui a plusieurs caries dentaires à faire traiter peut les faire traiter en une séance et, ainsi, il peut s'éviter des visites hebdomadaires chez le dentiste durant quatre à six mois et s'éviter le traumatisme psychique de ces visites.

Dans l'organisation d'une clinique externe pour la chirurgie et la dentisterie, il y a trois importantes exigences: (1) ménager le confort du malade, (2) rendre l'opération indolore, (3) fournir des conditions opératoires adéquates. Il ne fait aucun doute que tout risque pour la vie du malade en clinique externe, soit pour la chirurgie soit pour la dentisterie, se rattache à l'anesthésie. Il faut pouvoir offrir au malade le même degré de sécurité que l'hôpital ordinaire peut lui donner dans le même entourage. L'anesthésiologiste ne devrait travailler que dans des conditions qu'il estime les plus favorables à la sécurité du malade et, en conséquence, il doit être responsable des plans et de l'organisation de la clinique. Pratiquer l'anesthésie dans de telles circonstances requiert de l'expérience et de la compétence.

Le but de cet article est de décrire une clinique externe dirigée actuellement par l’auteur, clinique qui fonctionne à Vancouver depuis juillet 1965. L'anesthésiologiste doit fournir au médecin traitant une liste d'instructions qui exprime clairement où et quand se rendre et certains autres détails importants. L'anesthésiologiste doit interroger et examiner le malade et noter sur sa fiche tous les détails pouvant influencer l'évaluation préopératoire. Le défaut d'examen préopératoire aussi bien que l'absence d'interrogatoire exposent l'anesthésiologiste à des charges sérieuses.

Le plan physique de la clinique de l'auteur peut se voir (Fig. 1) et l'auteur décrit la conduite ordinaire de l'anesthésie des malades ambulants dans de telles circonstances. La Table II nous fait voir la liste des opérations qui peuvent être pratiquées en clinique externe d'après l'expérience acquise sur 1,500 malades. L'auteur fait également des suggestions pour répondre aux plaintes postopératoires les plus fréquentes de la part de ces malades.

\section{REFERENCES}

1. Poole, J. C.; Gardner, Claude; Smith, Frank; Carroll, J. I.; \& MacCartney, H. H. Standards of General Anaesthesia for Dental Surgery. B.C. M.J. 7: 405 (1965).

2. Treloar, E. James. Out-Patient Anaesthesia. B.C. M.J. 8: 419 (1966).

3. - - Pre-operative Anaesthetic Assessment and Premedication. College of General Practice of Canada J. 12: 4 (1966).

4. Weekes, F. Clinical Appraisal of Methohexital Sodium and Thiopental Sodium in the Ambulatory Patient. J. Oral Surg. 21: 386 (1963).

5. Corssen, G. \& Howard, J. Newer Intravenously Administered Anesthetics in Oral Surgery. J. Oral Surg. 21; 133 (1963). 